(aw)

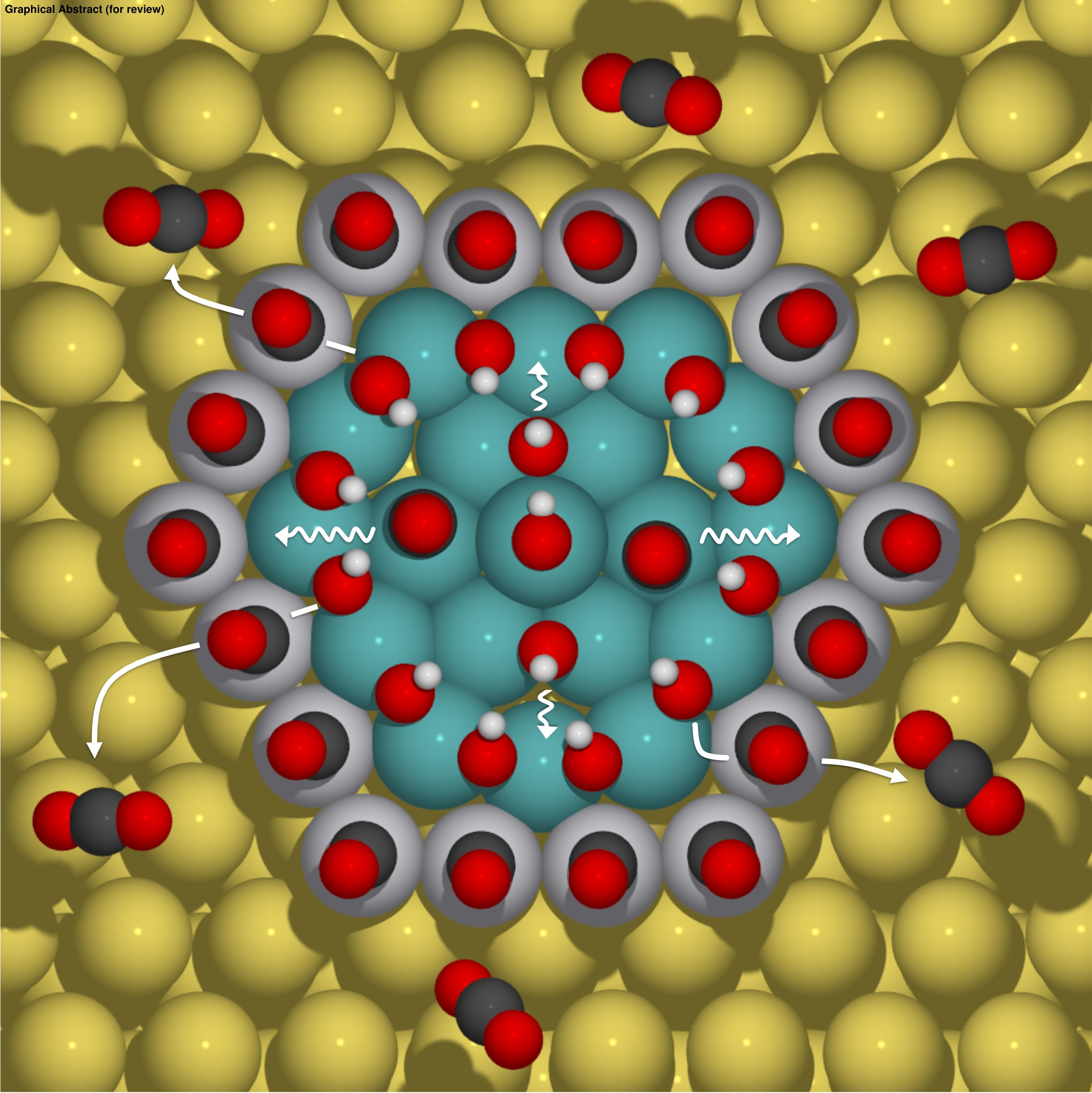




\title{
Novel 2D RuPt Core-Edge Nanocluster Catalyst for CO Electro-oxidation
}

\author{
Lars C. Grabow ${ }^{1, *}$, Qiuyi Yuan², Hieu A. Doan"1, Stanko R. Brankovic ${ }^{1,2, *}$ \\ ${ }^{1}$ Department of Chemical and Biomolecular Engineering \\ ${ }^{2}$ Department of Electrical and Computer Engineering \\ University of Houston, Houston TX, 77204
}

\begin{abstract}
A single layer, bi-metallic RuPt catalyst on $\mathrm{Au}(111)$ is synthesized using surface limited red-ox replacement of underpotentially deposited $\mathrm{Cu}$ and $\mathrm{Pb}$ monolayers though a two-step process. The resulting 2D RuPt monolayer nanoclusters have a unique core-edge structure with a Ru core and Pt at the edge along the perimeter. The activity of this catalyst is evaluated using $\mathrm{CO}$ monolayer oxidation as the probe reaction. Cyclic voltammetry demonstrates that the $2 \mathrm{D} \mathrm{RuPt}$ core-edge catalyst morphology is significantly more active than either $\mathrm{Pt}$ or $\mathrm{Ru}$ monolayer catalysts. Density functional theory calculations in combination with infra-red spectroscopy data point towards oscillating variations (ripples) in the adsorption energy landscape along the radial direction of the Ru core as the origin of the observed behavior. Both, $\mathrm{CO}$ and $\mathrm{OH}$ experience a thermodynamic driving force for surface migration towards the $\mathrm{Ru}-\mathrm{Pt}$ interface, where they adsorb most strongly and react rapidly. We propose that the complex interplay between epitaxial strain, ligand and finite size effects is responsible

\footnotetext{
Corresponding Authors: Theory and DFT Analysis: L. C. Grabow, grabow@uh.edu

Experiments: S.R. Brankovic, SRBrankovic@uh.edu
} 
for the formation of the rippled RuPt monolayer cluster, which provides optimal conditions for a quasi-ideal bi-functional mechanism for $\mathrm{CO}$ oxidation, in which $\mathrm{CO}$ is adsorbed mainly on $\mathrm{Pt}$, and $\mathrm{Ru}$ provides $\mathrm{OH}$ to the active $\mathrm{Pt}-\mathrm{Ru}$ interface.

CO oxidation; core-edge nanocluster; finite size effect; galvanic displacement; Density functional theory; electrocatalysis 


\section{Introduction}

Metal monolayers represent two-dimensional (2D) guest/host structures with fundamental and practical importance in the fields of electrocatalysis and fuel cells [110] as well as in gas-phase heterogeneous catalysis [11-16]. Their properties differ significantly from the corresponding bulk materials due to diverse structural and quantum effects $[7,8,11,17-22]$. In the monolayer (ML) configuration a guest metal forms nanoclusters of atomic height on the surface of a host metal up to the limit of a continuous overlayer. All guest atoms in the ML are exposed on the surface and experience the effect of the host substrate directly. The interaction between guest and host is manifested through structural contributions as epitaxial strain in the ML $[2,19,20]$ and through a ligand effect, i.e. the d-electrons' orbital mixing between the guest ML and the host $[4,10,11,18,20]$. According to modern theoretical considerations the energy of the $d$-band center relative to the Fermi level is a suitable descriptor of the resulting catalytic behavior of the ML surface [22,23]. In the case of host substrates, which are weak ligands, the $d$-band center position is mainly affected by the level of coherent strain $[19,23]$. Positive (tensile) strain results in an upward shift of the $d$-band center position towards the Fermi level and increased reactivity of the ML [24,25]. If the strain is negative (compressive), the opposite effect transpires. For host substrates, which are strong ligands, the ligand and strain effects are coupled and the net shift in the $d$-band center energy is a convolution of both $[11,20,22,23,26]$. We have recently 
demonstrated that, for monolayer catalysts below the continuous coverage limit, the size of the 2D guest nanoclusters also plays an important role in their overall catalytic behavior (finite size effect) [27]. In such a ML catalyst morphology consisting of 2D nanoclusters with a certain size, the active (or residual) strain, $\varepsilon$, in a nanoclusters is a linear combination of the epitaxial strain, $e$, and the strain caused by the finite size effects [28-30]. Hence, the active strain in a 2D nanocluster has a radial dependence and is more compressive at the periphery than in the center of the cluster $[27,30]$. For very small clusters, the contribution of the size dependent compressive strain component is significant and the active strain in the nanocluster can differ considerably from the one set by the epitaxial relation between the guest ML and the host substrate [27]. This fundamental effect can be used as additional knob to fine tune ML catalysts' properties by control of their morphology [31-33].

The work presented here is the next step in our quest for a better and more sophisticated ML catalyst design. We synthesized a novel, bi-metallic RuPt ML catalyst on $\mathrm{Au}(111)$ having Ru-metal as a core and Pt-metal at the edge along the perimeter. We term this 2D ML nanocluster catalyst structure a "core-edge" configuration (RuPtML$\mathrm{CE} / \mathrm{Au}(111))$. Cyclic voltammetry data for CO stripping (CO ML electro-oxidation) as a model reaction demonstrate that the bi-metallic RuPtmL-CE/Au(111) catalyst is significantly more active than either PtmL/Au(111) or RumL/Au(111) catalysts. Infra-Red Spectroscopy (IRS) and periodic Density Functional Theory (DFT) calculations point to 
a rich adsorption energy landscape of the RuPtML-CE nanocluster as the origin of the exceptional activity. The unique interplay of a large epitaxial lattice constant mismatch, weak ligand effects, and strong finite size effects lead to a surface reconstruction characterized by ripples, which are comparable to those observed on fluid interfaces that are dominated by surface tension, e.g., water/air [36]. We calculated that the resulting electronic structure variations along the radial direction of the $\mathrm{Ru}$ core provide a thermodynamic driving force for surface bound species to migrate to the catalytically active Ru-Pt interface. We propose that the combination of surface diffusion and interface kinetics leads to a quasi-ideal bi-functional mechanism for $\mathrm{CO}$ oxidation on RuPtmL-CE/Au(111) with very high activity.

\section{Experimental and Computational Methods}

\subsection{Catalyst Synthesis}

The $\mathrm{Au}(111)$ single crystal disk, $10 \mathrm{~mm}$ in diameter and $2 \mathrm{~mm}$ in thickness (Monocrystals Company), is prepared using several steps including mechanical polishing, electropolishing and hydrogen flame annealing [32]. Special attention is paid to avoid thermal reconstruction of $\mathrm{Au}(111)$ and consequent appearance of Au clusters on the surface upon immersion into the electrolyte. All solutions used in our experiments are made from ultra-high purity chemicals (99.999\%, Alfa Aesar, Merck) and 18.2 M $\Omega$ ultrapure water (Millipore Direct Q-UV with Barnstead A1007 pre- 
distillation unit). All potentials related to the UPD experiments are referenced as the value of underpotential $(\Delta \mathrm{E})$. The potentials in IR experiments are quoted with respect to a saturated calomel electrode (SCE). The $\mathrm{Pt}_{\mathrm{ML}} / \mathrm{Au}(111)$ and $\mathrm{RumL} / \mathrm{Au}(111)$ catalysts are deposited via surface limited red-ox reduction (SLRR) of Cuupd/Au(111) [34,35]. To synthesize $\mathrm{Cu} u p d / \mathrm{Au}(111)$ a complete $\mathrm{ML}$ of $\mathrm{Cu}$ is deposited onto $\mathrm{Au}(111)$ at $30 \mathrm{mV}$ underpotential from $10^{-3} \mathrm{M} \mathrm{Cu}^{2+}+0.1 \mathrm{M} \mathrm{HClO}_{4}$ solution. At these conditions, the $\mathrm{Cu}$ UPD ML forms a $2 \times 2$ structure on $\mathrm{Au}(111)$ with a coverage of $0.75[37,38]$. The SLRR solution for Pt or Ru ML deposition was $0.1 \mathrm{M} \mathrm{HClO}_{4}$ with $10^{-3} \mathrm{M}$ concentration of $\mathrm{Pt}(\mathrm{IV})$ or $\mathrm{Ru}(\mathrm{III})$ salts $\left(\mathrm{K}_{2} \mathrm{PtCl}_{6}\right.$ or $\left.\mathrm{RuCl}_{3}\right)$. Under these conditions, the lack of complexing ability of supporting electrolyte to $\mathrm{Cu}$ ions results in the situation where the main ligand of $\mathrm{Cu}$ ions is $\mathrm{Cl}^{-}$liberated from the depositing $\mathrm{Pt}$ and $\mathrm{Ru}$ ions. Therefore, the proposed stoichiometry of SLRR reactions assumes $\mathrm{Cu}^{+}$as the stable and predominant oxidation state of $\mathrm{Cu}$ ion, and the expected $\mathrm{Pt}$ and $\mathrm{Ru}$ ML coverage of $\mathrm{Au}(111)$ shown below [38]:

$$
\begin{aligned}
& 0.75 C u_{U P D} / A u(111)+0.75 \frac{1}{4} P t^{4+}=0.75 C u^{+}+0.18 P t_{M L} / A u(111) \\
& 0.75 C u_{U P D} / A u(111)+0.75 \frac{1}{3} R u^{3+}=0.75 C u^{+}+0.25 R u_{M L} / A u(111)
\end{aligned}
$$

The RuPtmL-cE/ $\mathrm{Au}(111)$ catalyst is deposited using a slightly more complex procedure. First, the Ruml/Au(111) is deposited as described above. In the second step, a small amount of $\mathrm{Pb}$ is deposited via UPD on RumL/Au(111) at $275 \mathrm{mV}$ underpotential. The $\mathrm{Pb}$ atoms are then replaced by $\mathrm{Pt}$ using either $10^{-3} \mathrm{M} \mathrm{K}_{2} \mathrm{PtCl}_{6}+0.1 \mathrm{M} \mathrm{HClO}_{4}$ or $10^{-3} \mathrm{M}$ 
$\mathrm{K}_{2} \mathrm{PtCl}_{4}+0.1 \mathrm{M} \mathrm{HClO}_{4}$ solutions. All UPD and SLRR solutions were de-aerated with ultra-pure argon for 2 hours before the experiments.

\subsection{Surface Characterization and Activity Testing}

All electrochemical experiments, including the ex-situ and in-situ scanning tunneling microscopy (STM) studies, are performed in a nitrogen-purged glove box. For the CV measurements for CO ML electro-oxidation (for brevity we simply use the term "CO oxidation" in the text), the catalyst surface is initially saturated with $\mathrm{CO}$ at $-100 \mathrm{mV}$ vs. SCE from a CO-saturated $0.1 \mathrm{M} \mathrm{HClO}_{4}$ solution at room temperature and ambient pressure. The solution is then purged for 2 hours with $\mathrm{N}_{2}$ to remove any excess $\mathrm{CO}$ from the bulk solution before the start of each CV or IR measurement. The sweep rate was $50 \mathrm{mVs}^{-1}$. After each deposition experiment, a number of STM images are recorded. The STM images are recorded using Nanoscope V controller with multimode scanner unit (Veeco Instruments) and analyzed using our custom made digital image processing algorithm [39,40]. In the case of Pb UPD on RumL/Au(111), in-situ STM measurements were obtained to elucidate the mechanistic details and morphology change during the initial stage of $\mathrm{Pb}$ UPD. The STM image analysis provided information about 2D nanocluster nucleation density, average size, coverage, and the nanoclusters height. Image segmentation is used for differentiation and identification of each nanocluster on the image/surface. For this purpose, a threshold value has been determined to segment 
each image into a binary image using an autonomous global thresholding method [41]. The error bar for image analysis results represents the standard deviation of the data obtained from analysis of all images used for a particular experiment.

The cell for in-situ IR spectro-electrochemical measurements, described previously [42], consisted of a ZnSe hemisphere serving as the attenuated total reflection (ATR) window and cell bottom, and a Teflon body. A Nicolet 6700 spectrometer and a BAS CV27 potentiostat are used to conduct our experiments. The collection of the spectra is computer controlled at a given potential of the working electrode set prior to data acquisition. The 128 scans with $4 \mathrm{~cm}^{-1}$ resolution are co-added in a single step. Spectra are given as $-\Delta R / R$ using the spectrum at the highest potential as the reference one where no $\mathrm{CO}$ adsorption occurs. The positive-going bands therefore represent a gain of a particular species at the sample potential relative to that at the reference potential.

\subsection{Computational Methods}

Periodic density functional theory (DFT) calculations were performed using the Vienna ab-initio simulation package (VASP) $[43,44]$ in the projector augmented wave (PAW) $[45,46]$ formulation and a kinetic cutoff energy of $400 \mathrm{eV}$. The revised PerdewBurke-Ernzerhof (GGA-RPBE) functional [47] was used to describe exchange and correlation. A Gaussian smearing with a Fermi temperature of $k_{b} T=0.1 \mathrm{eV}$ was 
employed and the total energy was subsequently extrapolated to $k_{b} T=0.0 \mathrm{eV}$ [48]. For geometry optimizations, forces were converged below $0.05 \mathrm{eV} / \AA$. All surface models were built within the Atomic Simulation Environment (ASE) [49]. Surfaces of Pt(111) and $\mathrm{Ru}(111)$ were modeled as five-layer $\mathrm{fcc}(111)$ slabs, where the top three layers were relaxed and the bottom two layers were fixed in their bulk positions. We used $\mathrm{Ru}(\mathrm{fcc})$ instead of $\mathrm{Ru}(\mathrm{hcp})$ as reference material to eliminate any effects caused by crystal structure changes when $\mathrm{Ru}$ is forced into the fcc symmetry when present as ML on the Au fcc host. The theoretically obtained lattice constants of $3.998 \AA$, $3.836 \AA$, and $4.215 \AA$ were found for $\mathrm{Pt}, \mathrm{Ru}(\mathrm{fcc})$, and $\mathrm{Au}$, respectively. These lattice constants correspond to atom-atom distances in the closed packed (111) plane of $2.83 \AA$, $2.69 \AA 2.98 \AA$ and are in reasonable agreement with the experimental values of $2.78 \AA$, $2.65 \AA$ (hcp), and $2.88 \AA$ for $\operatorname{Pt}(111), \operatorname{Ru}(0001)$, and $\operatorname{Au}(111)$ [50]. Calculations for $\operatorname{Pt}(111)$ and $\operatorname{Ru}(111)$ were performed in a (3x3) unit cell with a $(4 \times 4 \times 1)$ Monkhorst-Pack k-point [51] mesh. Slabs were separated with a vacuum spacing of $14 \AA$ along the normal $(z)$ direction of the surface. The monolayer core-edge system $\mathrm{RuPt}_{\mathrm{ML}-\mathrm{CE}} / \mathrm{Au}(111)$ was modeled as 37 atom cluster consisting of a Ru island surrounded by $\mathrm{Pt}$ atoms at the perimeter, supported on a (10x10) unit cell of $\mathrm{Au}(111)$ with four atomic layers. A VASP POSCAR file ("RuPt_Au111_POSCAR") of the relaxed RuPtML-CE/Au(111) structure is provided in the Supplementary Online Material. The size of the RuPt core-edge cluster is approximately $1.5 \mathrm{~nm}$ in diameter. Gamma-point only calculations of RuPtmL-CE/Au(111) were 
performed with the same constraints and vacuum separation as in the (3x3) unit cells. A dipole correction [52] to the electrostatic potential was included to separate adjacent unit cell images. Binding energies for $\mathrm{CO}$ and $\mathrm{OH}$ are provided with reference to the relaxed $\mathrm{RuPt}$ ML-CE $/ \mathrm{Au}(111)$ surface and the gas-phase species $\mathrm{CO}, \mathrm{H}_{2} \mathrm{O}$ and $\mathrm{H}_{2}$.

\section{Results}

\subsection{Pb UPD on RumL/Au(111) and RuPt $t_{M L-C E} / A u(111)$ Synthesis}

The prelude for RuPtmL-CE/Au(111) catalyst synthesis is Pb UPD on Ruml/Au(111). This process is examined in more detail by $\mathrm{CV}$ and STM in order to provide sufficient evidence for the formation of a core-edge structure of RuPtmL-CE/Au(111). The CV data for $\mathrm{Pb} \mathrm{UPD}$ on $\mathrm{RumL} / \mathrm{Au}(111)$ are shown in Figure 1A. The overall features of the voltammogram are very similar to the standard $\mathrm{Pb}$ UPD on $\mathrm{Au}(111)$. However the larger cathodic current and sub peak are observed at higher underpotentials $(\Delta \mathrm{E}>250$ $\mathrm{mV}$ ) due to a larger population of defects such as Ru nanocluster edges where the initial UPD process starts The onset of the UPD process starts with a broad cathodic peak shoulder evident at $\approx 510 \mathrm{mV} \Delta \mathrm{E}$. The main UPD features are associated with the sub peak centered at $\approx 250 \mathrm{mV}$ and the main deposition peak at $\approx 190 \mathrm{mV} \Delta \mathrm{E}$. The in-situ STM images recorded during Pb UPD on $\mathrm{RumL} / \mathrm{Au}(111)$ are shown in Figure 1B with the corresponding underpotentials annotated in the upper right corners. The quantitative analysis of these images is presented in Figure 2A-C. The initial RumL/Au(111) surface at 
$600 \mathrm{mV} \Delta \mathrm{E}$ has a $\mathrm{Ru}$ nanocluster population on $\mathrm{Au}(111)$ with $23 \%$ coverage and an average size of $12 \pm 3.0 \mathrm{~nm}^{2}$. The Ru ML coverage observed by STM is in good agreement with the coverage expected from the SLRR reaction stoichiometry, eq. 2 . The cathodic sweep towards $400 \mathrm{mV} \Delta \mathrm{E}$ does not produce any appreciable change on $\mathrm{RumL} / \mathrm{Au}(111)$. Analog to the $\mathrm{Pb} \mathrm{UPD}$ on $\mathrm{Au}(111)$, the cathodic current in the range $400 \mathrm{mV}<\Delta \mathrm{E}<500$ $\mathrm{mV}$ is most likely associated with Pb UPD on defects sites of the Au(111) surface [40].
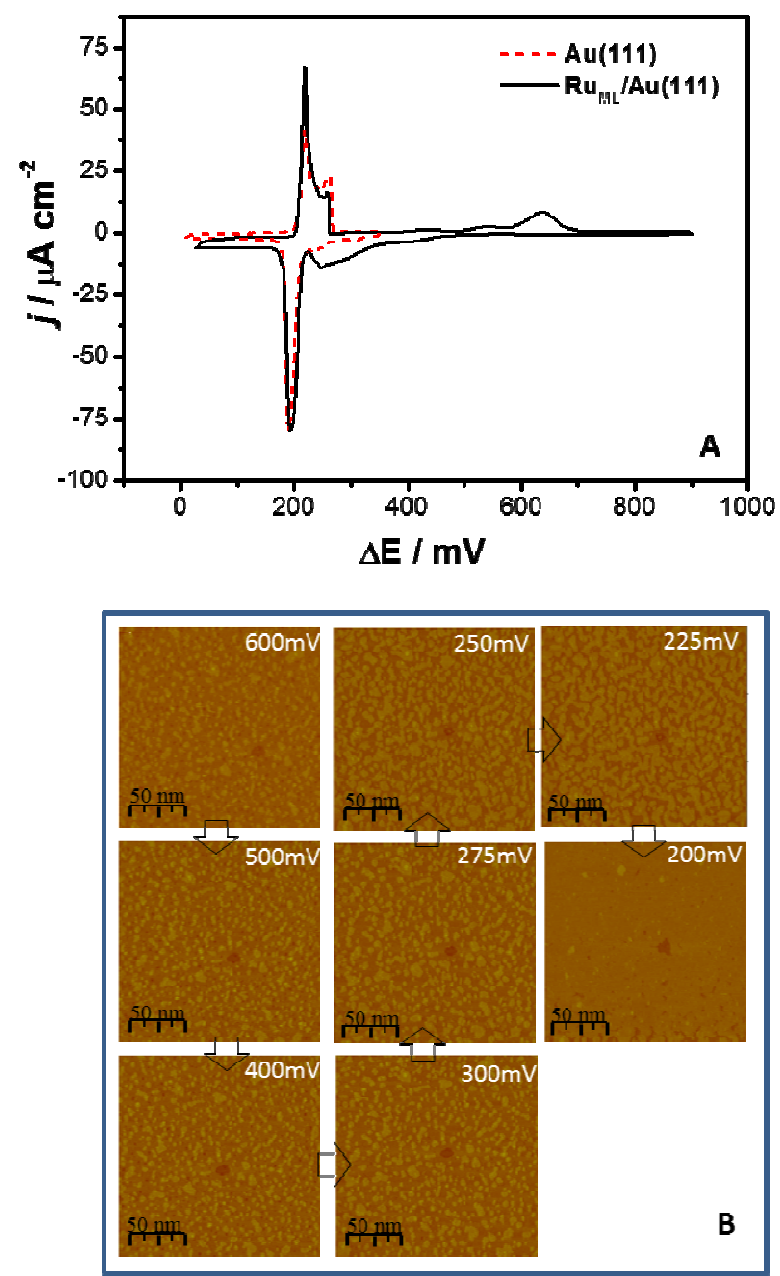
Figure 1. (A) Cyclic voltammogram of $\mathrm{Pb}$ UPD on $\mathrm{Au}(111)$ (dotted red) and on $\mathrm{RumL} / \mathrm{Au}(111)$ (solid black). Sweep rate $10 \mathrm{mVs}^{-1}$, solution: $10^{-3} \mathrm{M} \mathrm{Pb}^{2+}+\mathrm{HClO}_{4}$. (B) The STM image sequence recorded in-situ during Pb UPD on RumL/Au(111). The arrows in (B) indicate potential and temporal sequence of recorded STM images

Further sweep of the potential in cathodic direction produces a noticeable change in the RumL/Au(111) surface morphology. Below $300 \mathrm{mV} \Delta \mathrm{E}$, the 2D Ru nanoclusters start to show lateral growth quantified by an increase in their average size, Figure 1B and Figure 2C. Concurrently, the surface coverage of the $1^{\text {st }}$ layer starts to increase and the cluster density starts to decrease, Figure $2 \mathrm{~A}$ and $2 \mathrm{C}$. These data suggest that $\mathrm{Pb}$ UPD on $\mathrm{RumL} / \mathrm{Au}(111)$ proceeds by edge decoration of $\mathrm{Ru}$ nanoclusters with $\mathrm{Pb}$ adatoms, which appears as their lateral growth, i.e. the growth of $\mathrm{PbRu}$ nanoclusters. The process is schematically depicted in Figure 2D. At $250 \mathrm{mV} \Delta \mathrm{E}$ we observe the onset of nucleation of a $2^{\text {nd }} \mathrm{Pb}$ UPD layer on top of Ru nanoclusters (Figure $1 \mathrm{~B}$ and Figure $2 \mathrm{~A}$ C). 

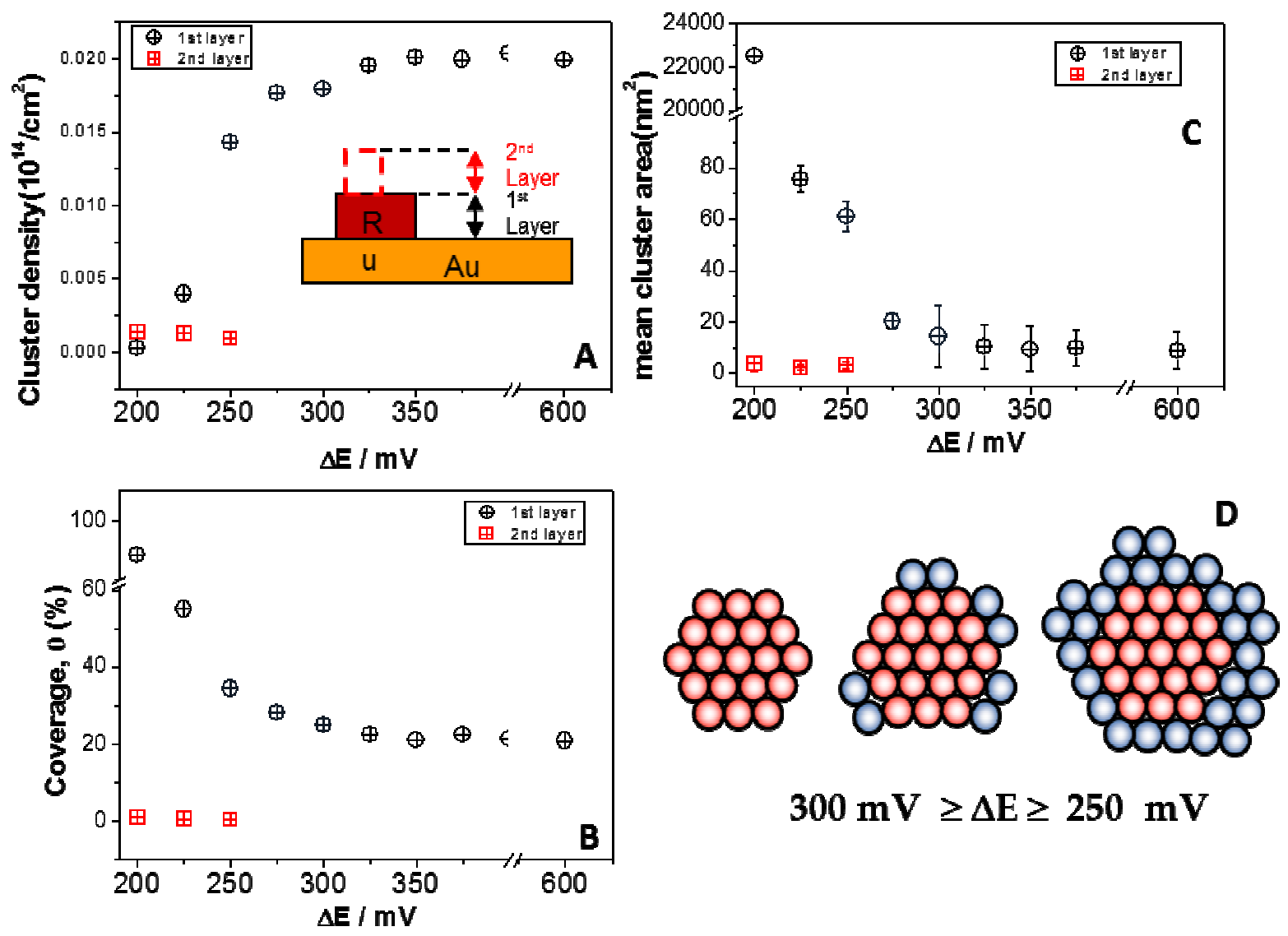

Figure 2. Results from STM image analysis: (A) nanocluster density vs. $\Delta \mathrm{E}$, inset shows the model with notation for the layers, (B) nanocluster coverage vs. $\Delta \mathrm{E}$, (C) mean nanocluster size vs. $\Delta \mathrm{E}$. (D) Schematic representation of the PbRu nanclusters (Ru- red, $\mathrm{Pb}$-blue) corresponding to the shaded area in graphs (A-C).

A further decrease of the underpotential and entering the main UPD peak at $\Delta \mathrm{E}=$ $200 \mathrm{mV}$ results in formation of a continuous Pb UPD layer on $\mathrm{Au}(111)$. This is evident by coalescence of growing $\mathrm{PbRu}$ nanoclusters into a complete $1^{\text {st }}$ layer while the properties of the $2^{\text {nd }}$ layer (on top of $\mathrm{Ru}$ ) remain more or less constant, Figure 2A-C. Clearly, the interesting underpotential region for the preparation of core-edge 
nanoclusters is the range between $300 \mathrm{mV}$ and $250 \mathrm{mV} \Delta \mathrm{E}$ (shaded regions, Figure 2). The $\mathrm{Pb}$ decorated $\mathrm{Ru}$ nanoclusters formed in this region provide a unique starting configuration that can be used for design and synthesis of bi-metallic PtRu nanoclusters with the desired core-edge structure. Indeed, this can be achieved by performing a second SLRR reaction between the $\mathrm{Pb}$ ad-atoms within the $\mathrm{PbRu}$ nanocluster and $\mathrm{Pt}$ ions. The general idea is outlined as cartoon in Figure 3. We note that the amount of deposited $\mathrm{Pt}$ at the perimeter of $\mathrm{Ru}$ nanoclusters is dependent on the SLRR reaction stoichiometry, i.e. the oxidation state of $\mathrm{Pt}$ ions $\left(\mathrm{Pt}^{\mathrm{n}+}\right)$, and the amount of $\mathrm{Pb}$ decorating the perimeter of $\mathrm{Ru}$ nanoclusters. The latter one depends on the $\triangle \mathrm{E}$ chosen for $\mathrm{Pb} \mathrm{UPD}$, which we fixed at $\Delta \mathrm{E}=275 \mathrm{mV}$ for the following reasons. First, this potential is the lowest underpotential at which the growth of a $2^{\text {nd }} \mathrm{Pb}$ layer on top of the $\mathrm{Ru}$ nanoclusters is not observed. This implies that the $\mathrm{PbRu}$ nanoclusters maintain their $2 \mathrm{D}$ configuration, Figure 1B and Figure 2A-C. Second, at this underpotential, the amount of $\mathrm{Pb}$ contained in the $\mathrm{PbRu}$ nanoclusters is truly limited to a decoration of the $\mathrm{Ru}$ nanoclusters' perimeter. Therefore, the same is expected for Pt deposited via the SLRR reaction. Further support for this interpretation is provided by our STM image analysis in Figure $2 \mathrm{C}$, which indicates that at $\Delta \mathrm{E}=275 \mathrm{mV}$ the $\mathrm{Ru}$ nanoclusters' average size increases from initially $12 \pm 3 \quad \mathrm{~nm}^{2} \quad(\operatorname{RumL} / \mathrm{Au}(111))$ to $21 \pm 1 \quad \mathrm{~nm}^{2}$ (Pbupd/Ruml/Au(111)@ $\Delta \mathrm{E}=275 \mathrm{mV})$. Assuming a compact nanocluster shape this corresponds to an increase of the nanoclusters' radius from $\mathrm{R}_{\mathrm{Ru}} \approx 2 \mathrm{~nm}$ to $\mathrm{R}_{\mathrm{PbRu}} \approx 2.6 \mathrm{~nm}$. 
The diameter of a $\mathrm{Pb}$ atom is $\approx 0.35 \mathrm{~nm}[50]$ and the difference between $\mathrm{R}_{\mathrm{Ru}}$ and $\mathrm{RPbRu}$ of $\approx 0.6 \mathrm{~nm}$ suggests that, on average, each $\mathrm{Ru}$ nanocluster has a continuous belt of $\mathrm{Pb}$ atoms at its perimeter, which is between one and two $\mathrm{Pb}$ atoms wide, Figure 3schematics.

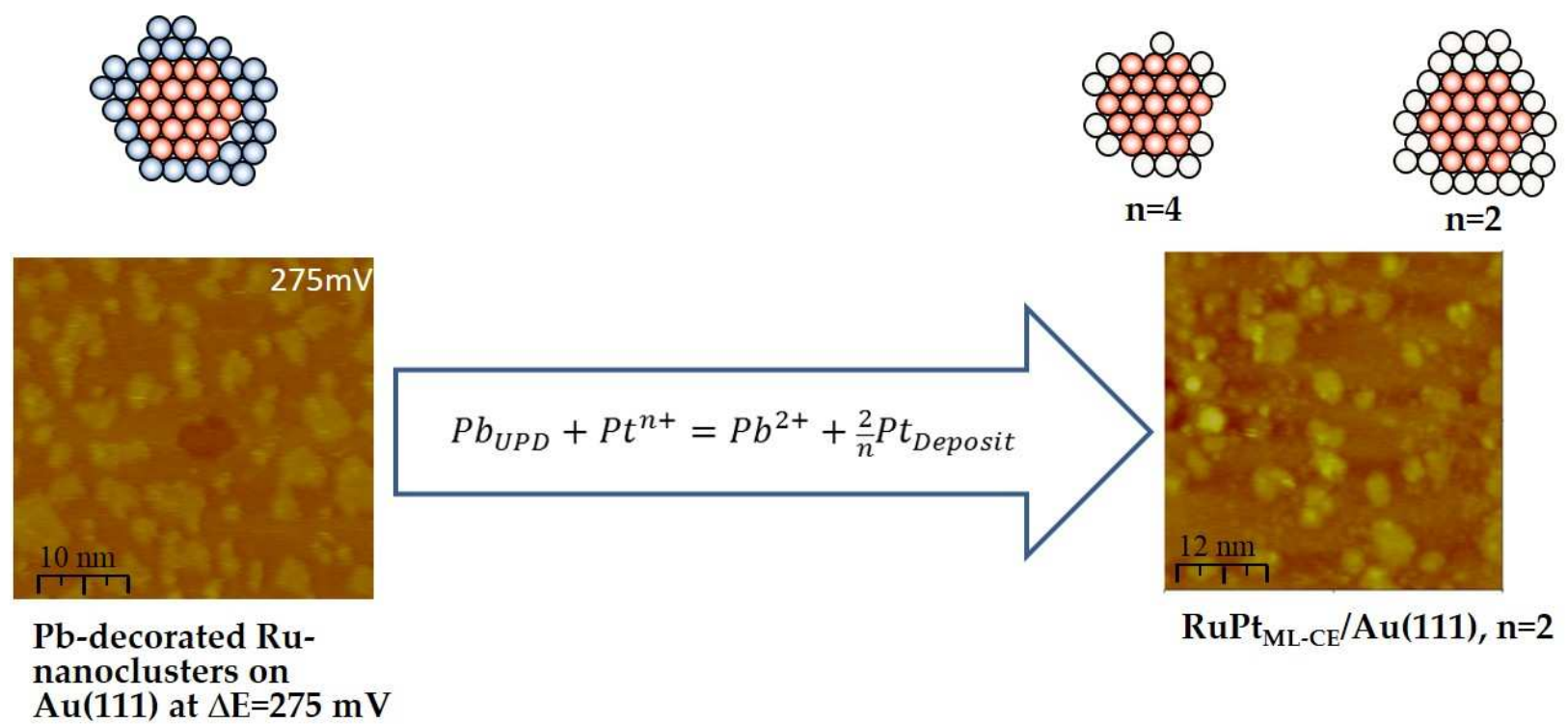

Figure 3. Representative STM image of the surface morphology for (left) Pbupd/Ruml/Au(111)@ $\Delta \mathrm{E}=275 \mathrm{mV}$, and (right) RuPtml-ce/Au(111) obtained from SLRR solution containing $\mathrm{Pt}^{2+}$. The cartoons above the STM images illustrate the proposed nanocluster structures $\left(\mathrm{Ru}\right.$ - red, $\mathrm{Pb}$ - blue, $\mathrm{Pt}$ - light gray, $n$ - oxidation state of $\mathrm{Pt}^{\mathrm{n}+}$ ion). The SLRR reaction stoichiometry within the arrow indicates the process causing the morphology change from left to right.

Based on these considerations, we can expect that Pt will deposit also as continuous belt around the perimeter of a $\mathrm{Ru}$ nanocluster (SLRR solution with $\mathrm{Pt}^{2+}$ ), or as an incomplete fractional decoration of the Ru nanoclusters' edge (SLRR solution with 
$\mathrm{Pt}^{4+}$ ), Figure 3-schematics. To provide further support for the formation of core-edge structures we include a representative STM image of RuPtmL-cE/Au(111) in Figure 3, which is obtained by SLRR of Pbupd/RumL/Au(111)@275 mV $\Delta$ E. The SLRR solution contained $\mathrm{Pt}^{2+}$. The presence of a $2^{\text {nd }}$ layer on some nanoclusters is evident and additional population of smaller nanoclusters in the $1^{\text {st }}$ layer, suggesting that besides a direct $\mathrm{Pb}$-Pt redox replacement, a local galvanic-cell mechanism for $\mathrm{Pt}$ deposition operates but to rather minor extent [34]. The STM characterization of RuPtmL-CE/Au(111) shows that the average size of a PtRu nanocluster is $\approx 19 \pm 0.6 \mathrm{~nm}^{2}$. This corresponds to a radius of $R_{P t R u} \approx 2.45 \mathrm{~nm}$. The size reduction of PtRu nanoclusters compared to the initial $\mathrm{PbRu}$ morphology $\left(\mathrm{R}_{\mathrm{PtRu}} \approx 2.45 \mathrm{~nm}\right.$ vs. $\mathrm{R}_{\mathrm{PbRu}} \approx 2.6 \mathrm{~nm}$.) is expected. Some loss of $\mathrm{Pb}$ on the surface during SLRR is possible due to the presence of residual $\mathrm{O}_{2}$ in solution $\left(<10^{-}\right.$ $\left.{ }^{6} \mathrm{M}\right)$ and thus, less $\mathrm{Pt}$ is deposited than expected from the SLRR reaction stoichiometry. In an ideal one-to-one exchange between $\mathrm{Pb}$ and $\mathrm{Pt}$ during the SLRR reaction, the smaller radius of $\mathrm{PtRu}$ nanoclusters is expected also as a result of smaller Pt atoms replacing larger $\mathrm{Pb}$ atoms at the nanocluster perimeter. Indeed, the observed difference between $R_{P t R u}$ and $R_{P b R u}$ of $0.15 \mathrm{~nm}$ is very close to the calculated difference in dimensions between $\mathrm{Pt}$ and $\mathrm{Pb}$ two-atom wide perimeters decorating Ru nanoclusters $\left(2\left(\mathrm{dPb}-\mathrm{dPt}_{\mathrm{Pt}}\right)=0.158 \mathrm{~nm}\right)$. 


\subsection{CO Monolayer (ML) Oxidation}

The CVs for CO ML electro-oxidation on different $\mathrm{Ru}$ and Pt morphologies on $\mathrm{Au}(111)$ are shown in Figure 4. In Figure 4A, we compare two different RuPtmL${ }_{\mathrm{CE}} / \mathrm{Au}(111)$ catalyst morphologies, in which the blue (black) line indicate data for the RuPtmL-CE/Au(111) catalyst obtained from SLRR solution containing $\mathrm{Pt}^{2+}\left(\mathrm{Pt}^{4+}\right)$ ions. In Figure 4B the $\mathrm{CVs}$ for $\mathrm{CO}$ oxidation on $\mathrm{Pt} \mathrm{t}_{\mathrm{ML}} / \mathrm{Au}(111)$ (green), and $\mathrm{RumL} / \mathrm{Au}(111)$ (red) catalysts are shown as reference. The very early onset of $\mathrm{CO}$ oxidation $(\mathrm{E}<100 \mathrm{mV})$ on both $\mathrm{RuPt}_{\mathrm{ML}-\mathrm{CE}} / \mathrm{Au}(111)$ catalysts is quite remarkable and significantly lower than either $\mathrm{Pt}_{\mathrm{ML}} / \mathrm{Au}(111)$ or $\mathrm{RumL} / \mathrm{Au}(111)$. The positive charge under the main anodic peaks, which correspond to $\mathrm{CO}$ oxidation $(300 \mathrm{mV}<\mathrm{E}<350 \mathrm{mV})$, is comparable for these two configurations ( $110 \mu \mathrm{C} \cdot \mathrm{cm}^{-2}$ for black and $130 \mu \mathrm{C} \cdot \mathrm{cm}^{-2}$ for blue curve). As expected, the configuration with more $\mathrm{Pt}$ also has a larger anodic charge related to $\mathrm{CO}$ stripping. For both Ru-PtML-CE/Au(111) configurations the $\mathrm{CO}$ stripping charge is slightly larger than one would expect based on the geometrical coverage of the Au surface by Pt-Ru clusters $(\approx 30 \%)[53,54]$, which suggests that the Pt perimeter of the RuPtML-CE clusters, i.e. Pt steps on $\mathrm{Au}(111)$, may serve as additional adsorption sites for $\mathrm{CO}$. The potential of the main CO oxidation peak for both RuPtmL-CE/ $\mathrm{Au}(111)$ catalysts (340 mV -black and 380 $\mathrm{mV}$ blue line) is shifted to slightly more positive potentials than on RumL/Au(111) (290 mV-red line, Figure 4B) or on a polycrystalline PtRu alloy with 1:1 atomic ratio [55]. The CO oxidation peaks for both RuPtmL-CE/Au(111) catalysts share a common characteristic 
current plateau feature appearing before the main $\mathrm{CO}$ oxidation peak. The magnitude of the current in the plateau region is approximately equal $\left(j \approx 10 \mu \mathrm{Acm}^{-2}\right)$ for both configurations. This is an interesting result which indicates that, in the initial stage of $\mathrm{CO}$ oxidation on RuPtmL-CE/Au(111) surfaces, the reaction is not kinetically limited but rather transport controlled. Transport limitations for $\mathrm{CO}$ adsorption from solution can be excluded, because the CO ML is already pre-adsorbed on the catalyst surface and it is the only CO present [55]. Hence, the transport limitations must originate from surface diffusion of one or more reacting species to a catalytically active site.
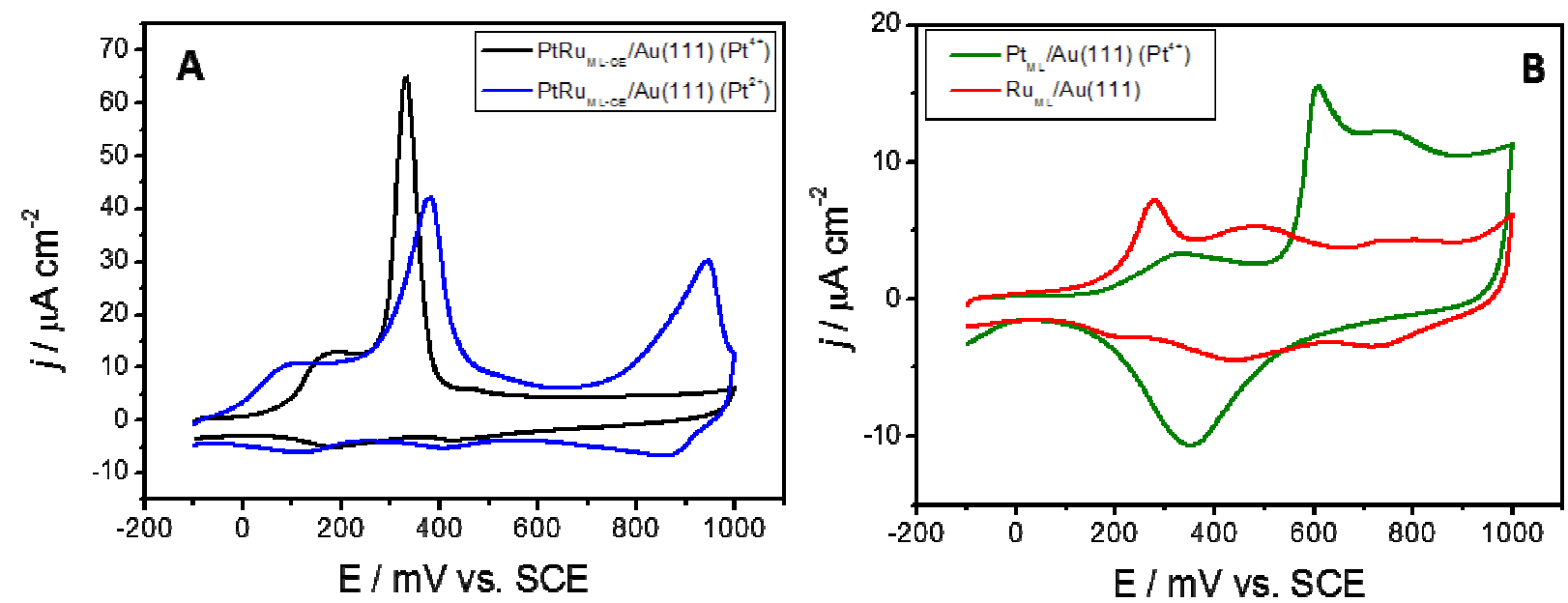

Figure 4. Cyclic voltammogram (CV) for CO oxidation on (A) RuPtmL-CE/Au(111) and (B) PtmL/Au(111) and RumL/Au(111). Solution: $0.1 \mathrm{M} \mathrm{HClO}_{4}$, sweep rate $50 \mathrm{mVs}^{-1}$, CO ML adsorbed at $-100 \mathrm{mV}$, upon which the solution is purged for 2 hours with $\mathrm{N}_{2}$. 
Further investigation of the data in Figure $4 \mathrm{~A}$ indicates that RuPtmL-CE/ $/ \mathrm{Au}(111)$ $\left(\mathrm{Pt}^{2+}\right)$ with more $\mathrm{Pt}$ at the perimeter appears to be more active, i.e., the onset of $\mathrm{CO}$ oxidation is observed at $100 \mathrm{mV}$ more negative potential $(\mathrm{E} \approx 0 \mathrm{mV})$ than for RuPtmL${ }_{\mathrm{CE}} / \mathrm{Au}(111)\left(\mathrm{Pt}^{4+}\right)$ with less $\mathrm{Pt}(\mathrm{E} \approx 100 \mathrm{mV})$. Approaching the anodic sweep limit, the same $\mathrm{RuPt}_{\mathrm{ML}-\mathrm{CE}} / \mathrm{Au}(111)\left(\mathrm{Pt}^{2+}\right)$ catalyst also shows a reversible anodic/cathodic peak centered at $\mathrm{E} \approx 900 \mathrm{mV}$, which is absent on the $\mathrm{CV}$ for $\mathrm{RuPt}$ ML-CE $/ \mathrm{Au}(111)\left(\mathrm{Pt}^{4+}\right)$ with less $\mathrm{Pt}$ at the perimeter. We associate this feature with the oxidation/reduction cycle of $\mathrm{Pt}$, which is part of the $\mathrm{RuPt}_{\mathrm{ML}-\mathrm{CE}} / \mathrm{Au}(111)\left(\mathrm{Pt}^{2+}\right)$ catalyst. This difference might indicate that Pt-like behavior tends to be preserved in $\mathrm{RuPt}_{\mathrm{ML}-\mathrm{CE}} / \mathrm{Au}(111)\left(\mathrm{Pt}^{2+}\right)$ where $\mathrm{Pt}$ has a larger presence at the perimeter of the PtRu nanocluster. The earlier onset of $\mathrm{CO}$ oxidation could be also related to this structural difference.

In contrast, the $\mathrm{CO}$ stripping data in Figure $4 \mathrm{~B}$ for $\mathrm{Pt}_{\mathrm{ML}} / \mathrm{Au}(111)$ and RumL/Au(111) show much lower activity. The magnitude of anodic currents related to $\mathrm{CO}$ oxidation are almost an order of magnitude lower as compared to RuPtML${ }_{\mathrm{CE}} / \mathrm{Au}(111)$. One possible reason for this difference could be the lower coverage of $\mathrm{Ru}(\approx$ $23 \%)$ and $\mathrm{Pt}(\approx 15 \%)$ of the $\mathrm{Au}(111)$ surface and therefore, a smaller total amount of adsorbed $\mathrm{CO}$ as compared to $\mathrm{RuPt}$ ML-CE/ $\mathrm{Au}(111)(\approx 30 \%)$. However, the difference of peak currents between $\operatorname{Pt}_{\mathrm{ml}} / \mathrm{Au}(111), \quad \operatorname{RumL} / \mathrm{Au}(111)$ and $\operatorname{RuPt}_{\mathrm{ML}-\mathrm{CE}} / \mathrm{Au}(111)$ is significantly larger than the respective coverage difference, which suggests that other effects play a role. The $\mathrm{Pt} \mathrm{t}_{\mathrm{M}} / \mathrm{Au}(111)$ surface appears to have faster $\mathrm{CO}$ oxidation 
kinetics (higher current density $j$ ) than RumL/Au(111), although the main peak for $\mathrm{CO}$ oxidation occurs at much more positive potential $\left(\mathrm{E}=650 \mathrm{mV}\right.$ for $\mathrm{Pt}_{\mathrm{ML}} / \mathrm{Au}(111) \mathrm{vs} . \mathrm{E}=$ $290 \mathrm{mV}$ for $\mathrm{Ruml} / \mathrm{Au}(111)$ ). The main peak position for RumL/Au(111), however, coincides roughly with the onset of the main peak for RuPtML-CE/Au(111), indicating that the reacting species on $\mathrm{RumL} / \mathrm{Au}(111)$ and $\mathrm{RuPt}_{\mathrm{ML}-\mathrm{CE}} / \mathrm{Au}(111)$ are thermodynamically equivalent. The drastic increase in $\mathrm{CO}$ oxidation kinetics on RuPtmL-CE/Au(111) can only be attributed to reaction sites at the Pt-Ru interface, which are absent for $\mathrm{Pt}_{\mathrm{ML}} / \mathrm{Au}(111)$ or $\mathrm{RumL} / \mathrm{Au}(111)$.

\subsection{Subtractively Normalized Fourier Transform Infra-Red Spectroscopy (SNFTIRS) Results}

An adsorbed $\mathrm{CO}$ molecule forms $\sigma$ and $\pi$ bonds with a transition metal surface (Pt and $\mathrm{Ru}$ ). The $\pi$ bond represents sizable contribution to the adsorption energy $[23,56]$, and is formed by back donation of metal $d$-electrons into the $\pi *$-antibonding molecular orbital of CO. Changes in the $d$-band center energy of a specific surface metal atoms (M) due to strain, ligand or 2D finite size effects influence the strength of $\mathrm{M}-\mathrm{CO}$ and $\mathrm{C}=\mathrm{O}$ bonds simultaneously [21]. A shift in $d$-band center energy of surface metal atoms can be assessed indirectly by observing changes in the $\mathrm{C}=\mathrm{O}$ bond stretching frequency of an adsorbed $\mathrm{CO}$ molecule. More $\delta-\pi *$ back donation results in a stronger metal $\mathrm{M}-\mathrm{CO}$ bond, but, at the same time, a weaker $\mathrm{C}=\mathrm{O}$ bond, which lowers its stretch frequency. 
Hence, a shift of the $\mathrm{C}=\mathrm{O}$ stretching band towards lower wave numbers can be qualitatively interpreted as an increase in $\mathrm{M}-\mathrm{CO}$ bond strength as long as $\mathrm{CO}$ binds to the same type of metal [56]. A direct comparison of $\mathrm{C}=\mathrm{O}$ stretch frequencies and binding strength between different metals, e.g. Pt and $\mathrm{Ru}$, is unfortunately not feasible, because of other energetic contributions to the $\mathrm{M}-\mathrm{CO}$ bond that are not captured by the $\delta-\pi *$ back donation model [23].

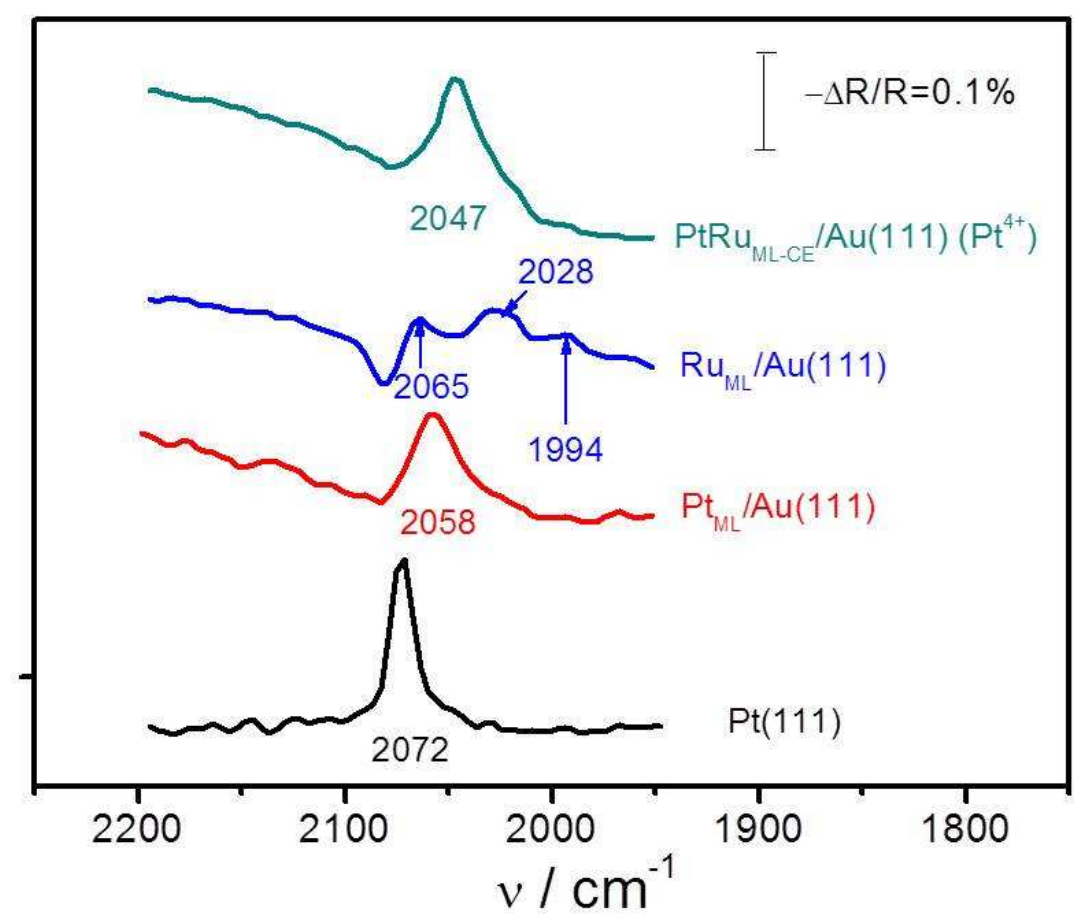

Figure 5. SNFTIR spectra for CO adsorption on different ML catalysts and $\operatorname{Pt}(111)$. Spectra recorded at $100 \mathrm{mV}$ in $0.1 \mathrm{M} \mathrm{HClO}_{4}$ solution; reference spectra taken at $900 \mathrm{mV}$. Spectra are offset for clarity. 
In Figure 5, Subtractively Normalized Fourier Transform Infra Red Spectroscopy (SNFTIRS) data are shown for CO adsorbed at $0.1 \mathrm{~V}$ vs. SCE on several different ML catalyst surfaces and $\mathrm{Pt}(111)$ as reference. The focus of our discussion is on the position of the stretching band of linearly bonded $\mathrm{CO}, v_{c}$, which contains qualitative information pertaining to the binding preference and strength of $\mathrm{CO}$ on the RuPtmL${ }_{\mathrm{CE}} / \mathrm{Au}(111)$ surface. In the case of $\mathrm{RumL} / \mathrm{Au}(111)$, the main peak is asymmetric and observed at $2065 \mathrm{~cm}^{-1}$. In close proximity to the main peak towards lower wave numbers a more complex peak structure develops. We can discern two additional peaks at 2028 and $1994 \mathrm{~cm}^{-1}$. The latter one is very weak and almost comparable to the noise level. A comparison to $\mathrm{Ru}(0001), v_{c O}=2011 \mathrm{~cm}^{-1}$ [57], indicates that the two peaks above $2011 \mathrm{~cm}^{-1}$, including the main peak, correspond to $\mathrm{CO}$ on $\mathrm{RumL} / \mathrm{Au}(111)$ that is more weakly bound than on $\mathrm{Ru}(0001)$. The small peak at $1994 \mathrm{~cm}^{-1}$ is consistent with a minority fraction of $\mathrm{CO}$ that is more strongly adsorbed than on $\mathrm{Ru}(0001)$. If we assume an epitaxial $\mathrm{Ru} \mathrm{ML}$ on $\mathrm{Au}(111)$, the average strain in $\mathrm{Ru}$ nanoclusters is positive and a strain-only based argument predicts only stronger CO binding, the opposite of what our experiment shows. The non-intuitive observations of weaker binding and multiple SNFTIR peaks will be explained in the computational section and are caused by a reconstruction of the $\mathrm{Ru}$ cluster to form concentric ripples. The $v_{\mathrm{CO}}$ for RuPtML$\mathrm{CE} / \mathrm{Au}(111)$ has a lower wave number $\left(2047 \mathrm{~cm}^{-1}\right)$ than either $\operatorname{Pt}(111)\left(2072 \mathrm{~cm}^{-1}\right)$, $\mathrm{Pt}_{\mathrm{ML}} / \mathrm{Au}(111)\left(2058 \mathrm{~cm}^{-1}\right)$ or $\mathrm{RumL} / \mathrm{Au}(111)\left(2065 \mathrm{~cm}^{-1}\right)$, which is consistent with $\mathrm{CO}$ 
binding most strongly to RuPtmL-CE/Au(111). We also observe a similar peak shape for $\mathrm{RuPt}_{\mathrm{ML}-\mathrm{CE}} / \mathrm{Au}(111)$ and $\mathrm{Pt}_{\mathrm{ML}} / \mathrm{Au}(111)$.

\subsection{Density Functional Theory (DFT) Simulations}

\subsubsection{RuPt $t_{\mathrm{ML}-\mathrm{CE}} / \mathrm{Au}(111)$ Surface Model}

The idealized model of the RuPtmL-CE/Au(111) surface used in our DFT analysis is shown in Figure 6A,B after geometry relaxation. The $\mathrm{Ru}$ and $\mathrm{Pt}$ atoms in the initial configuration were placed in a planar geometry on top of the $\mathrm{Au}(111)$ surface and their lateral distance was determined by the Au lattice constant, i.e., $\mathrm{Ru}$ and Pt experienced significant positive (expansive) lateral strain as determined by the lattice constant mismatch. On the basis of the calculated metal-metal atom distance, $d_{M}$, in the fcc $(111)$ plane the expansive strain $e=\frac{d_{A u}-d_{M}}{d_{M}}$ was $9.9 \%$ for $\mathrm{M}=\mathrm{Ru}$ and $5.4 \%$ for $\mathrm{M}=\mathrm{Pt}$. Using experimentally obtained values and the $\mathrm{hcp}(0001)$ plane for $\mathrm{Ru}$ as reference, the strain is less severe and reduces to $6.7 \%$ for $\mathrm{Ru}$ and $3.9 \%$ for Pt [50]. The anticipated outcome with this initial configuration was a stretched out RuPtML-CE nanocluster, which mostly assumes the Au lattice constant and exhibits reduced strain at the cluster perimeter due to compensation by finite size effects [28-30]. Upon optimization, however, the compressive finite size effects outweighed the expansive epitaxial strain and in 
combination with the weak ligand effect between $\mathrm{Au}$ and $\mathrm{Ru}$ or $\mathrm{Pt}$, the initially stretched RuPtmL-CE nanocluster contracted to a final geometry with negative (compressive) strain. To quantify the compressive strain, we averaged the bond distances within each concentric ring of the model system, Figure $6 \mathrm{~A}$, and related the change to the equilibrium lattice constant for the bulk fcc system. For the single $\mathrm{Ru}$ atom at the center, we considered its bond lengths to the surrounding six $\mathrm{Ru}$ atoms. From this analysis we obtain $\varepsilon=-0.4 \%$ for $\mathrm{Ru}_{\text {central, }} \varepsilon=-6.7 \%$ for Ruinner, $\varepsilon=-6.1 \%$ for Ruouter, and $\varepsilon=-6.8 \%$ for Pt. Given that the model cluster radius of ca. $0.75 \mathrm{~nm}$ is smaller than the experimentally synthesized clusters $\left(R_{P t R u} \approx 2.45 \mathrm{~nm}\right.$ ), the cluster contraction caused by finite size effects is likely overestimated in our simulations. Yet, during the optimization of a continuous $\mathrm{Ru} \mathrm{ML}$ on $\mathrm{Au}(111)$ in a $(3 \times 3)$ unit cell, we also observed the contraction of the $\mathrm{Ru}$ layer and the formation of a patchy surface. Since the continuous overlayer is representative of a very large Ru particle, we can conclude from these results that the lattice constant mismatch between $\mathrm{Ru}$ and $\mathrm{Au}$ is too large and the ligand effect between $\mathrm{Ru}$ and $\mathrm{Au}$ too weak to maintain an epitaxial relationship at any cluster size. Hence, finite size effects can be expected to dominate in this system. This surprising result could not have been anticipated, but is important to understand the unique CO ML electro-oxidation behavior of this catalyst. 

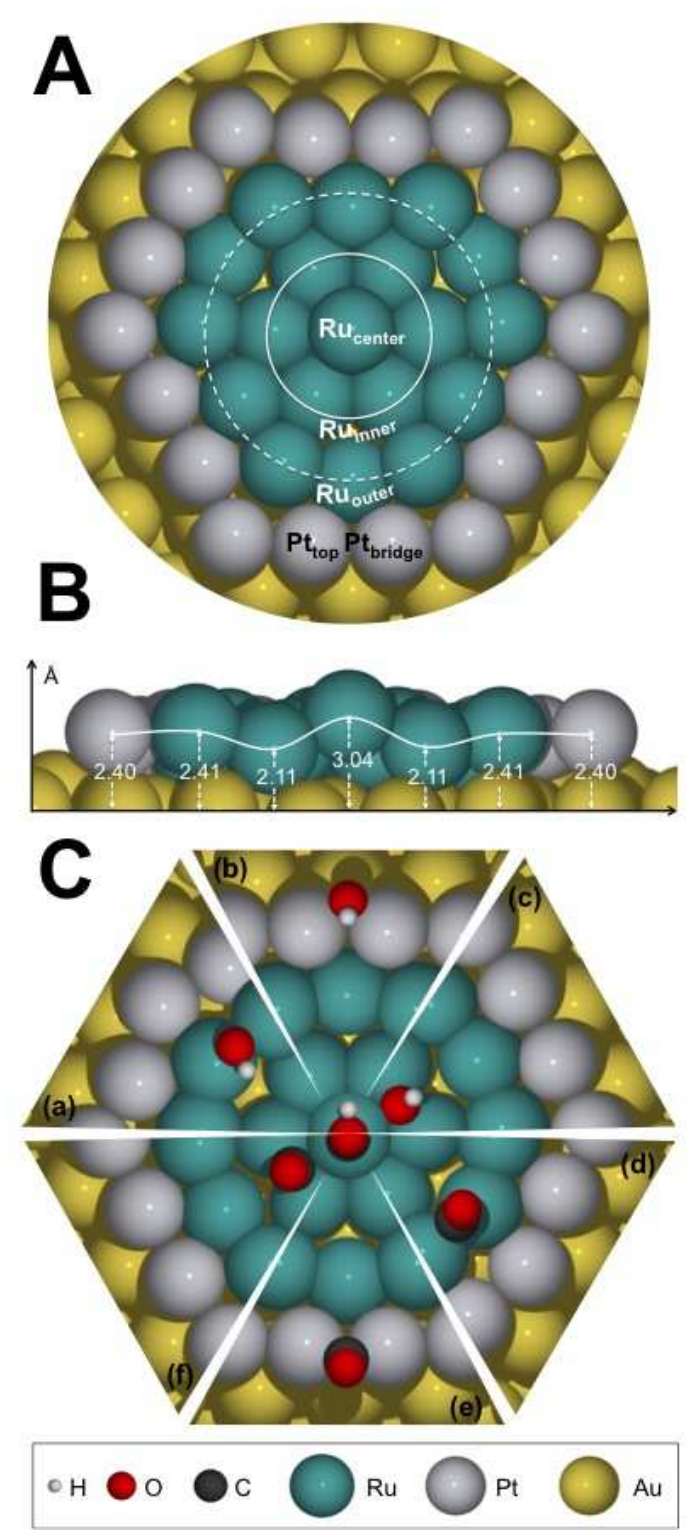

Figure 6. DFT calculated equilibrium structures. (A) Top view and (B) cut through the center of a ca. $1.5 \mathrm{~nm}$ RuPtmL-CE cluster on $\mathrm{Au}(111)$. The average height of each concentric ring of $\mathrm{Ru}$ or $\mathrm{Pt}$ above the $\mathrm{Au}(111)$ surface is indicated in (B). (C) Position of the most stable calculated adsorption sites for $\mathrm{OH}(\mathrm{a}-\mathrm{c})$ and $\mathrm{CO}(\mathrm{d}-\mathrm{f})$ on the different concentric rings: a - OH on Ruouter; b - OH on Pt; c-OH on Ruinner; $\mathrm{d}-\mathrm{CO}$ on Ruouter; e $\mathrm{CO}$ on $\mathrm{Pt}$; $\mathrm{f}-\mathrm{CO}$ on Ruinner. Adsorption of $\mathrm{OH} / \mathrm{CO}$ on the central $\mathrm{Ru}$ atom (Rucentral) is also depicted. 
Associated with the strong RuPt $\mathrm{ML}-\mathrm{CE}$ nanocluster compression we observe vertical rippling of the $2 \mathrm{D}$ cluster, Figure $6 \mathrm{~B}$. In the final structure, the Ru core consists of alternating high and low concentric atomic rings, where the height variation is more pronounced towards the cluster center. The position of the $\mathrm{Ru}$ central atom is $0.93 \AA$ higher above the $\mathrm{Au}(111)$ surface than the Ruinner ring. By moving upwards the $\mathrm{Ru}$ central atom can escape the strong compression and reduce its local strain to $-0.4 \%$. Ru atoms in the Ruouter ring are only ca. $0.4 \AA$ higher than $\mathrm{Ru}$ atoms in the $\mathrm{Ru}$ inner ring and at approximately the same height as the surrounding Pt atoms. We find that the interplay between epitaxy, finite size and ligand effects in this system lead to a complex nanocluster structure with spatial variations in its geometry, and consequently, its catalytic behavior.

\subsubsection{OH adsorption on $\mathrm{RuPt}_{\mathrm{ML}-\mathrm{CE}} / \mathrm{Au}(111)$}

The reconstruction of the RuPtmL-CE/Au(111) surface leads to a rich adsorption energy landscape for $\mathrm{OH}$ and $\mathrm{CO}$ as summarized in Table 1. The geometries of preferred binding configurations on each concentric ring of the RuPtML-CE/Au(111) surface are given in Figure 6C. We find that $\mathrm{OH}$ binds very strongly to the elevated $\mathrm{Ru} \mathrm{u}_{\text {central site }}$ and bridge sites on the raised Ruouter ring. The most stable position for $\mathrm{OH}$ is on a bridging Ruouter site located directly at the Ru-Pt interface of the core-edge 
structure, where it binds ca. $0.7 \mathrm{eV}$ more strongly than on the $\mathrm{Ru}(111)$ surface. In contrast, the $\mathrm{OH}$ binding energy on bridge sites of the lower laying Ruinner ring is $0.16 \mathrm{eV}$ weaker than on $\mathrm{Ru}(111)$. Simple strain arguments would have suggested that the compressed $\mathrm{Ru}$ surface binds generally weaker than the equilibrated $\mathrm{Ru}(111)$ surface, but our DFT results indicate the presence of strong binding sites on the elevated and more exposed $\mathrm{Ru}$ atoms. This demonstrates that strain arguments only apply to scenarios with no or moderate surface relaxation. $\mathrm{OH}$ binding to $\mathrm{Pt}$ is as unfavorable on the $\mathrm{RuPt}_{\mathrm{ML}-\mathrm{CE}} / \mathrm{Au}(111)$ surface as it is on $\mathrm{Pt}(111)$ and no significant $\mathrm{OH}$ coverage on $\mathrm{Pt}$ sites can be expected. If one extrapolates these results to a larger, yet contracted, $\mathrm{RumL} / \mathrm{Au}(111)$ cluster, we expect that every other (elevated) row binds $\mathrm{OH}$ strongly, whereas the lower laying rows in between bind $\mathrm{OH}$ weaker than the $\mathrm{Ru}(111)$ surface. Thus, diffusion of adsorbed $\mathrm{OH}$ in the outward radial direction towards the strongly binding Ru-Pt interface is hindered by the rippled surface morphology. If we simply take the binding energy difference between $\mathrm{OH}$ adsorption on $\mathrm{Rucentral}$ and $\mathrm{Ru}$ inner as an estimate of the minimum required diffusion barrier, we obtain ca. $0.6 \mathrm{eV}$. With the addition of even just a small kinetic barrier this implies that $\mathrm{OH}$ is trapped at a certain distance from the nanocluster center and cannot easily diffuse along the radial direction or reach the Ru-Pt interface unless a sufficient potential is applied. 
Table 1. Calculated $\mathrm{CO}$ and $\mathrm{OH}$ binding energies. Bolded values represent the most stable binding energies for $\mathrm{Pt}(111)$ and $\mathrm{Ru}(111)$. For $\mathrm{RuPt}_{\mathrm{ML}-\mathrm{CE}} / \mathrm{Au}(111)$ the most stable sites on $\mathrm{Pt}$ and each $\mathrm{Ru}$ ring are given in bold face and correspond to the geometries shown in Figure 6C.

\begin{tabular}{cccc}
\hline \multirow{2}{*}{ Surface } & $\begin{array}{c}\text { Adsorption } \\
\text { site }\end{array}$ & Eco $(\mathrm{eV})$ & EOH $(\mathrm{eV})$ \\
\hline \multirow{3}{*}{$\operatorname{Pt}(111)$} & top & -1.73 & 1.63 \\
& bridge & -1.76 & $\mathbf{0 . 6 3}$ \\
& fcc & $\mathbf{- 1 . 7 8}$ & 0.90 \\
& hcp & -1.75 & 1.25 \\
\hline & top & $\mathbf{- 1 . 7 4}$ & 0.62 \\
$\operatorname{Ru}(111)$ & bridge & -1.67 & -0.04 \\
& fcc & -1.50 & $-\mathbf{0 . 1 0}$ \\
& hcp & -1.68 & -0.05 \\
\hline & Pttop & -2.02 & 0.38 \\
& Ptbridge & $\mathbf{- 2 . 1 2}$ & $\mathbf{0 . 5 2}$ \\
& Ruouter/top & -2.12 & - \\
$\mathrm{RuPt}$ ML-CE/Au(111) & Ruouter/bridge & $\mathbf{- 2 . 1 9}$ & $\mathbf{- 0 . 8 3}$ \\
& Ruinner/top & -1.67 & - \\
& Ruinner/bridge & $\mathbf{- 1 . 8 5}$ & 0.06 \\
& Rucenter & $\mathbf{- 1 . 9 5}$ & -0.56 \\
\hline
\end{tabular}

\subsubsection{CO Adsorption on RuPt $t_{M L-C E} / A u(111)$}

The reconstructed $\mathrm{RuPt}_{\mathrm{ML}-\mathrm{CE}} / \mathrm{Au}(111)$ surface offers a variety of binding sites for $\mathrm{CO}$ as given in Table 1 and shown in Figure $6 \mathrm{C}(\mathrm{d}-\mathrm{f})$. $\mathrm{CO}$ adsorption on a top site of the $\mathrm{Pt}$ ring $\left(\mathrm{E}_{\mathrm{co}}=-2.02 \mathrm{eV}\right)$ is stronger than on a top site of $\mathrm{Pt}(111)\left(\mathrm{E}_{\mathrm{co}}=-1.73 \mathrm{eV}\right)$. If $\mathrm{CO}$ adsorbs on a Ptbridge site of RuPtmL-CE/Au(111), Figure 6C(e), its binding strength increases to $\mathrm{E}_{\mathrm{CO}}=-2.12 \mathrm{eV}$. The bridge site is also the preferred site for $\mathrm{CO}$ adsorption on the outer 
and inner Ru ring. Before we continue the presentation of the $\mathrm{CO}$ adsorption results, we need to address the well-documented problem of standard GGA-DFT methods to predict correct adsorption site preferences and its implication for the present study [58,59]. The SNFTIRS data in Figure 5 provide experimental evidence for on-top adsorption of $\mathrm{CO}$ on RuPtmL-CE/Au(111) and show the $v_{c o}$ signal associated with on-top adsorbed CO. The maximum difference between on-top and bridge adsorption in Table 1 is $0.18 \mathrm{eV}$ for Ruinner and less than $0.1 \mathrm{eV}$ for all other locations. The narrow preference between these high symmetry sites is consistent with a previous DFT study [60]. As it turns out, it does not matter if we base our radial adsorption analysis given below on the most stable $\mathrm{CO}$ adsorption site according to DFT, e.g. bridge, or by restricting $\mathrm{CO}$ adsorption to the experimentally observed on-top positions only. For complete transparency, however, we report both, the most stable and the on-top binding energy, but we have limited the graphical depiction of binding sites in Figure 6C to the most stable geometries only.

As we have observed for $\mathrm{OH}$, the elevated outer $\mathrm{Ru}$ row is most reactive and binds $\mathrm{CO}$ stronger $\left(\mathrm{E}_{\mathrm{c} o, \text { bridge }}=-2.19 \mathrm{eV}\right.$, Figure $6 \mathrm{C}(\mathrm{d})$, Eco,top $\left.=-2.12 \mathrm{eV}\right)$ than the lower laying inner Ru row (Eco,bridge $=-1.85 \mathrm{eV}$, Figure $6 \mathrm{C}(\mathrm{f})$, Eco,top $-1.67 \mathrm{eV})$. On Rucentral we predict that $\mathrm{CO}$ binds to the top site with an intermediate binding energy of Eco $=-1.95$ $\mathrm{eV}$. Contrary to $\mathrm{OH}$, the energy difference between $\mathrm{CO}$ adsorption on $\mathrm{Ru}$ center and $\mathrm{Ru}$ inner is only ca. $0.1 \mathrm{eV}(0.28 \mathrm{eV}$ for on-top adsorption only), and therefore much less 
pronounced. On the basis of these calculated adsorption energies, we can deduce that (i) the $\mathrm{CO}$ binding energy landscape across $\mathrm{RuPt}_{\mathrm{ML}-\mathrm{CE}} / \mathrm{Au}(111)$ is relatively flat, (ii) $\mathrm{CO}$ binds preferentially to the Ru-Pt interface, and (iii) $\mathrm{CO}$ binding on the compressed $\mathrm{RuPt}_{\mathrm{ML}-\mathrm{CE}} / \mathrm{Au}(111)$ cluster is unexpectedly stronger than on the equilibrated $\mathrm{Pt}(111)$ or $\mathrm{Ru}(111)$ reference surfaces. The former two results suggests that $\mathrm{CO}$ is relatively mobile on the surface and diffuses much more readily than $\mathrm{OH}$ in the radial direction to reach its preferred adsorption site at the Ru-Pt interface. The latter result confirms that geometry relaxation in high strain situations with weak ligand effects can become the dominant driver for changes in adsorption energy.

\section{Discussion}

We used UPD and SLRR to synthesize a unique RuPt core-edge structure on $\mathrm{Au}(111)$, and confirmed its 2D geometry using STM. CV experiments demonstrate superior thermodynamic and kinetic $\mathrm{CO}$ oxidization behavior compared to the $\mathrm{RumL}_{\mathrm{m}} / \mathrm{Au}(111)$ and $\mathrm{Pt}_{\mathrm{ML}} / \mathrm{Au}(111)$ catalysts (Figure 4). The measured current density per atom is significantly higher than previously reported values [55]. This large activity increase is not easily explained, but insight into the atomic-scale relaxation and equilibrium structure in the context of the experimental observations and previous 
literature can elucidate some of the mechanistic details and provide a qualitative description of the dominant catalytic features of RuPtmL-CE/Au(111).

For the mechanistic discussion we consider five key steps: (i) CO adsorption until saturation is reached; (ii) $\mathrm{H}_{2} \mathrm{O}$ electro-oxidation and formation of adsorbed $\mathrm{OH}$; (iii) displacement of $\mathrm{CO}$ with $\mathrm{OH}$ (does not contribute to $\mathrm{CV}$ signal); (iv) $\mathrm{CO}$ oxidation (contributes to $\mathrm{CV}$ signal); and (v) possible surface diffusion of $\mathrm{CO}$ and $\mathrm{OH}$ to active sites. Here, $\mathrm{CO}$ adsorption can be ruled out as differentiating step, because a CO saturated surface is the initial coverage in all cases. Certainly important, however, is the preference to displace $\mathrm{CO}$ versus $\mathrm{CO}$ oxidation as $\mathrm{OH}$ starts to form. Earlier work has shown that $\mathrm{Ru}(0001)$ has low activity for $\mathrm{CO}$ oxidation due to a strong $\mathrm{Ru}-\mathrm{OH}$ interaction and non-reactive displacement of pre-adsorbed CO [61]. Hence, we may qualitatively conclude that on $\mathrm{Ru}$ the barrier for $\mathrm{CO}$ oxidation is larger than for $\mathrm{H}_{2} \mathrm{O}$ oxidation and its $\mathrm{CO}$ oxidation activity measured in $\mathrm{CV}$ experiments depends largely on the competitive adsorption between $\mathrm{CO}$ and $\mathrm{OH}$. $\mathrm{Pt}(111)$ on the other hand, is easily saturated with $\mathrm{CO}$ and its activity is limited by $\mathrm{H}_{2} \mathrm{O}$ oxidation and the availability of $\mathrm{OH}$ [54]. Finally, surface diffusion only plays a role where the catalyst has spatially distributed reactions sites, such as the RuPt core-edge nanoclusters.

We begin with a discussion of the competitive adsorption between $\mathrm{CO}$ and $\mathrm{OH}$. For the sake of simplicity and ease of comparison with SNFTIRS data, we consider only 
on-top adsorption for $\mathrm{CO}$ and use the difference $\Delta \mathrm{Eco-oH}=\mathrm{Eco}-\mathrm{EoH}$ as indicator for preferential occupation of a site by $\mathrm{CO}$ or $\mathrm{OH}$. A more negative value indicates a larger preference for $\mathrm{CO}$ adsorption. For $\mathrm{Ru}(111)$ we obtain $\Delta \mathrm{Eco- \textrm {oH }}=-1.64 \mathrm{eV}$ and for $\mathrm{Pt}(111)$ $\Delta \mathrm{E}_{\mathrm{Co}-\mathrm{oH}}=-2.36 \mathrm{eV}$. By comparison to the above mentioned experimental observations [54,61] we propose a rule of thumb stating that adsorption sites with $\Delta$ Eсо-он $<-2.3 \mathrm{eV}$ are preferentially occupied by $\mathrm{CO}$ and contribute to the measured $\mathrm{CO}$ oxidation current, whereas $\Delta \mathrm{Eco-oн}>-1.6 \mathrm{eV}$ indicates preferential coverage by $\mathrm{OH}$ and simple desorption of $\mathrm{CO}$ (no oxidation). For $-2.3 \mathrm{eV}<\Delta$ Eco-oh $<-1.6 \mathrm{eV}$ we assume a mix of $\mathrm{CO}$ and $\mathrm{OH}$ coverage, as well as mixed $\mathrm{CO}$ desorption and oxidation.

Table 2. Preferential coverage prediction based on $\Delta \mathrm{E}$ со-OH $=$ Eсо - Eон comparison with $\mathrm{Pt}(111)$ and $\mathrm{Ru}(111)$. On top adsorption of $\mathrm{CO}$ is assumed unless otherwise noted.

\begin{tabular}{cccc}
\hline Surface & Location & $\begin{array}{c}\Delta \mathrm{ECO}_{\mathrm{OH}}=\mathrm{E} \mathrm{EO}-\mathrm{EOH} \\
(\mathrm{eV})\end{array}$ & $\begin{array}{c}\text { Preferentially } \\
\text { occupied by }\end{array}$ \\
\hline $\mathrm{Pt}(111)$ & - & -2.36 & $\mathrm{CO}$ \\
\hline $\mathrm{Ru}(111)$ & - & -1.64 & $\mathrm{OH}$ \\
\hline & $\mathrm{Pt}$ & -2.40 & $\mathrm{CO}$ \\
$\mathrm{RuPt}$ ML-CE/ $\mathrm{Au}(111)$ & $\mathrm{Ru}$ outer & -1.29 & $\mathrm{OH}$ \\
& $\mathrm{Ru}$ & -1.73 & $\mathrm{OH} / \mathrm{CO}$ \\
& $\mathrm{Ru}$ & $-1.91(\mathrm{CO}$ on bridge $)$ & $\mathrm{OH}$ \\
\hline
\end{tabular}

The values of $\Delta$ Eco-or for RuPtmL-CE/Au(111) and the expected occupancy of each site are tabulated in Table 2. This qualitative and simplified analysis predicts that $\mathrm{CO}$ 
adsorbs preferentially on the Pt ring with a binding energy that is $0.29 \mathrm{eV}$ stronger than on $\mathrm{Pt}(111)$. The $\mathrm{Ru}$ sites on elevated rings (Rucenter, Ruouter) are covered by $\mathrm{OH}$ after $\mathrm{CO}$ displacement and also bind $\mathrm{OH}$ significantly more strongly than $\mathrm{Ru}(111)$. For the lower laying $\mathrm{Ru}$ sites ( $\mathrm{Ru}$ inner) $\Delta \mathrm{Eco-oH}$ is in between the limiting values established by $\mathrm{Ru}(111)$ and $\mathrm{Pt}(111)$ and we must assume mixed occupation with $\mathrm{OH}$ and $\mathrm{CO}$. These sites also show generally weaker interactions with $\mathrm{CO}$ and $\mathrm{OH}$ compared to $\mathrm{Ru}(111)$, indicating a lower total coverage of these sites.

Our theoretical prediction of site occupation on $\mathrm{RuPt}_{\mathrm{ML}-\mathrm{CE}} / \mathrm{Au}(111)$ agrees well with the SNFTIRS data shown in Figure 5. When no Pt sites are available, CO must adsorb on $\mathrm{Ru}$ sites, on which Eco has an oscillating radial dependence. $\mathrm{CO}$ binds strongly to elevated rows, but weakly to low laying rows. This is reflected by the existence of multiple $v_{c o}$ peaks for RumL/Au(111) in our SNFTIRS data that correspond to strongly and weakly adsorbed CO molecules. If we also consider the preferential occupations predicted in Table 2, most $\mathrm{CO}$ is adsorbed on the weak binding Ruinner sites where $\mathrm{E}_{\mathrm{co}}=-1.67 \mathrm{eV}$ is weaker than on $\mathrm{Ru}(111), \mathrm{E}_{\mathrm{CO}}=-1.74$. This is again consistent with the occurrence of the main $v_{c o}$ peak for Ruml/Au(111) at higher wave numbers than on $\operatorname{Ru}(0001)$.

When Pt is present in the RuPtmL-CE/ $\mathrm{Au}(111)$ system, $\mathrm{CO}$ preferentially adsorbs to the Pt belt, resulting in a single SNFTIRS peak that has a similar shape as in the case of 
$\mathrm{Pt}_{\mathrm{ML}} / \mathrm{Au}(111)$. The observed shift of $\nu_{c o}$ from $2072 \mathrm{~cm}^{-1}$ on Pt(111) to $2047 \mathrm{~cm}^{-1}$ on RuPtmL${ }_{\mathrm{CE}} / \mathrm{Au}(111)$ is consistent with the stronger calculated binding energy of $\mathrm{CO}$ on the Pt site of RuPtmL-cE/Au(111) compared to $\mathrm{Pt}(111)$. Overall, our theoretical and experimental data suggest that before the onset of CO oxidation the Pt sites of the RuPtmL-CE/Au(111) surface are saturated with CO. CO initially adsorbed on elevated Ru sites is displaced by $\mathrm{OH}$ and a smaller amount of $\mathrm{CO}$ can be found adjacent to $\mathrm{OH}$ species on Ru sites of lower laying Ru rings.

The CV behavior of $\mathrm{CO}$ oxidation on RuPtmL-CE/Au(111) in Figure 4 can now be discussed in terms of the spatial site distribution and surface diffusion. As stated before, the near order of magnitude higher activity of RuPtML-CE/Au(111) must be attributed to highly reactive sites at the Ru-Pt interface. At the beginning of the potential sweep the interface consists of $\mathrm{CO}$ on $\mathrm{Pt}$ sites in direct vicinity of $\mathrm{OH}$ species adsorbed on $\mathrm{Ru}$ and the reaction may proceed immediately. In contrast to $\mathrm{Pt}_{\mathrm{ML}} / \mathrm{Au}(111), \mathrm{CO}$ oxidation in this scenario is not limited by $\mathrm{OH}$ supply. The earlier reaction onset in the case of the wider $\mathrm{Pt}$ belt $\left(\mathrm{Pt}^{2+}\right)$ is likely related to weaker bound $\mathrm{Pt}-\mathrm{CO}$ at the $\mathrm{Ru}$-Pt interface. For a two (or more) Pt atom wide belt, $\mathrm{Pt}$ atoms at the interface have an average coordination number of 9 and are expected to be less reactive than Pt atoms directly at the edge, which have a coordination number of 7 [62]. This interpretation is consistent with the observation of the $\mathrm{Pt}$ oxidation/reduction cycle for $\mathrm{RuPt}_{\mathrm{ML}-\mathrm{CE}} / \mathrm{Au}(111)\left(\mathrm{Pt}^{2+}\right)$, which indicates the preservation of Pt-like behavior. 
Once the initial $\mathrm{CO} / \mathrm{OH}$ at the interface is rapidly depleted, the oxidation reaction displays a current plateau in the CV graph, which is independent on the Pt belt width and indicates a transport limited process. Indeed, our DFT results indicate that there is a thermodynamic driving force for radial $\mathrm{CO}$ and $\mathrm{OH}$ diffusion from the core area towards the Ru-Pt interface, but the rippled cluster surface shown in Figure $6 \mathrm{~B}$ with strong and weak binding $\mathrm{Ru}$ rows slows the diffusion process. While $\mathrm{CO}$ has a small diffusion barrier, the diffusion barrier for $\mathrm{OH}$ was estimated to be at least $0.6 \mathrm{eV}$ or higher. These largely immobile $\mathrm{OH}$ species on elevated Ru rows form concentric circles that trap $\mathrm{CO}$ in the Ru core area and cause the diffusion limited plateau region observed in the $\mathrm{CV}$ measurements.

As the potential reaches the potential of the main oxidation peak for RumL/Au(111) (ca. $290 \mathrm{mV}$ ) the Ru core region of RuPtML-CE/Au(111) becomes active for $\mathrm{CO}$ oxidation, but with rather slow $\mathrm{CO}$ oxidation kinetics. Yet, the reaction onset in the $\mathrm{Ru}$ core region temporarily removes blocking $\mathrm{OH}$ species and allows mobile $\mathrm{CO}$ species to quickly migrate radially outwards to the strongly binding Ru-Pt interface. In the absence of transport limitations the $\mathrm{CO}$ oxidation reaction occurs rapidly at the $\mathrm{Ru}-\mathrm{Pt}$ interface associated with a drastic increase in current density observed in the CV graph (Figure 4). The described mechanism is consistent with all experimental observations and computational data. It is also a prototype example of a truly bifunctional 
mechanism in which $\mathrm{Ru}$ and $\mathrm{Pt}$ form an active interface and each component contributes an individual functionality.

\section{Conclusions}

Using a two-step process consisting of underpotential deposition techniques and surface limited red-ox replacement we have synthesized a novel 2D core-edge monolayer catalyst morphology. The core-edge nanoclusters are deposited on $\mathrm{Au}(111)$ and are composed of a Ru core surrounded by a Pt edge, RuPtmL-CE/Au(111). STM analysis confirms that the synthesized 2D core-edge nanoclusters are of monoatomic height and $\mathrm{CV}$ experiments confirm their superior $\mathrm{CO}$ electro-oxidation activity that exceeds the activity of RumL/Au(111) and $\mathrm{Pt}_{\mathrm{ML}} / \mathrm{Au}(111)$ by nearly an order of magnitude. The unique catalytic activity of the RuPt $\mathrm{ML}-\mathrm{CE} / \mathrm{Au}(111)$ catalyst is explained in terms of its rich adsorption energy landscape, which is a direct result of the surface reconstruction of the $\mathrm{Ru}$ core to form concentric ripples. The ripple formation in this particular system is caused by a large epitaxial lattice mismatch, weak ligand effects, and strong finite size effects. The characteristics of the adsorption energy landscape of the rippled core-edge structure were determined by a combination of DFT calculations and SNFTIRS experiments and point towards thermodynamically favorable radial transport from the $\mathrm{Ru}$ core to the active $\mathrm{Ru}-\mathrm{Pt}$ interface. In addition, the ripples lead to alternating strong 
and weak binding sites, which are likely populated with $\mathrm{OH}$ and an $\mathrm{OH} / \mathrm{CO}$ adlayer, respectively. The diffusion of $\mathrm{OH}$ in the radial direction is slow, while $\mathrm{CO}$ is relatively mobile. Based on the experimental and computational data we propose a mechanism in which immobile $\mathrm{OH}$ species prevent $\mathrm{CO}$ diffusion and cause a transport controlled current plateau in the $\mathrm{CV}$ graph at low potentials. At higher potentials the Ru core region becomes active for $\mathrm{CO}$ oxidation leading to temporary removal of $\mathrm{OH}$. This allows rapid diffusion of $\mathrm{CO}$ in the $\mathrm{Ru}$ core region to the $\mathrm{Ru}-\mathrm{Pt}$ interface, where it can rapidly react. The proposed mechanism is truly bi-functional with two spatially separated domains and a catalytically active interface site. We postulate that the investigated RuPtmL-CE/Au(111) catalyst has (electrochemical) applications beyond $\mathrm{CO}$ oxidation, e.g. methanol oxidation, and that analogous core-edge structures with different metal components can be synthesized. Our synthesis technique for the preparation of this novel 2D morphology opens up a new and entirely unexplored design space for monolayer catalysts, specifically if a reaction can benefit from bifunctional catalytic behavior.

\section{Acknowledgments}

The experimental material is based upon work supported by the National

Science Foundation under the contract CHE-0955922. LCG and HAD acknowledge 
financial support from the National Science Foundation and the U.S. Department of Energy under contract NSF/DOE CBET-1258688. Use of the computational resources at the Center for Nanoscale Materials was supported by the U.S. DOE, Office of Science, Office of Basic Energy Sciences, under contract no. DE-AC02-06CH11357. Additional computational resources were provided by the Center for Advanced Computing and Data Systems (CACDS) and the Research Computing Center (RCC) at the University of Houston.

\section{References}

[1] J.L. Zhang, M.B. Vukmirovic, Y. Xu, M. Mavrikakis, R.R. Adžć, Angew. ChemieInternational Ed. 44 (2005) 2132.

[2] L.A. Kibler, A.M. El-Aziz, R. Hoyer, D.M. Kolb, Angew. Chemie Int. Ed. 44 (2005) 2080 .

[3] J. Zhang, M.B. Vukmirovic, K. Sasaki, A.U. Nilekar, M. Mavrikakis, R.R. Adžíć, J. Am. Chem. Soc. 127 (2005) 12480.

[4] J. Zhang, K. Sasaki, E. Sutter, R.R. Adží, Science (80-. ). 315 (2007) 220.

[5] A. Kowal, M. Li, M. Shao, K. Sasaki, M.B. Vukmirovic, J. Zhang, N.S. Marinkovic, P. Liu, A.I. Frenkel, R.R. Adžíc, Nat. Mater. 8 (2009) 325.

[6] S.R. Brankovic, J.X. Wang, R.R. Adžić, Electrochem. Solid-State Lett. 4 (2001) A217.

[7] R. Adží, J. Zhang, K. Sasaki, M. Vukmirovic, M. Shao, J. Wang, A. Nilekar, M. Mavrikakis, J. Valerio, F. Uribe, Top. Catal. 46 (2007) 249. 
[8] K. Sasaki, J.X. Wang, H. Naohara, N. Marinkovic, K. More, H. Inada, R.R. Adžić, Electrochim. Acta 55 (2010) 2645.

[9] A. Nilekar, Y. Xu, J. Zhang, M. Vukmirovic, K. Sasaki, R. Adžíc, M. Mavrikakis, Top. Catal. 46 (2007) 276.

[10] M.P. Hyman, J.W. Medlin, J. Phys. Chem. C 111 (2007) 17052.

[11] J.R. Kitchin, J.K. Nørskov, M.A. Barteau, J.G. Chen, Phys. Rev. Lett. 93 (2004) 4.

[12] J. Greeley, M. Mavrikakis, Nat. Mater. 3 (2004) 810.

[13] S. Alayoglu, A.U. Nilekar, M. Mavrikakis, B. Eichhorn, Nat. Mater. 7 (2008) 333.

[14] J. Knudsen, A.U. Nilekar, R.T. Vang, J. Schnadt, E.L. Kunkes, J.A. Dumesic, M. Mavrikakis, F. Besenbacher, J. Am. Chem. Soc. 129 (2007) 6485.

[15] M.P. Hyman, B.T. Loveless, J.W. Medlin, Surf. Sci. 601 (2007) 5382.

[16] N. Schumacher, K. Andersson, L.C. Grabow, M. Mavrikakis, J. Nerlov, I. Chorkendorff, Surf. Sci. 602 (2008) 702.

[17] P.A. Dowben, Surf. Sci. Rep. 40 (2000) 151.

[18] J. Greeley, J.K. Nørskov, M. Mavrikakis, Annu. Rev. Phys. Chem. 53 (2002) 319.

[19] M. Mavrikakis, B. Hammer, J.K. Nørskov, Phys. Rev. Lett. 81 (1998) 2819.

[20] A. Schlapka, M. Lischka, A. Gross, U. Käsberger, P. Jakob, Phys. Rev. Lett. 91 (2003) 016101.

[21] E. Kampshoff, E. Hahn, K. Kern, Phys. Rev. Lett. 73 (1994) 704.

[22] A. Ruban, B. Hammer, P. Stoltze, H.L. Skriver, J.K. Nørskov, J. Mol. Catal. A Chem. 115 (1997) 421.

[23] T. Bligaard, J.K. Nørskov, Electrochim. Acta 52 (2007) 5512.

[24] L. Grabow, Y. Xu, M. Mavrikakis, Phys. Chem. Chem. Phys. 8 (2006) 3369.

[25] J. Wintterlin, T. Zambelli, J. Trost, J. Greeley, M. Mavrikakis, Angew. ChemieInternational Ed. 42 (2003) 2850. 
[26] S.R. Brankovic, J. McBreen, R.R. Adžić, J. Electroanal. Chem. 503 (2001) 99.

[27] S.-E. Bae, D. Gokcen, P. Liu, P. Mohammadi, S.R. Brankovic, Electrocatalysis 3 (2012) 203.

[28] "Size Effects in Catalysis by Supported Metal Clusters" by A.A. Kolmakov, D.W. Goodman, in: S.N. Khanna, A.W. Castleman (Eds.), Quantum Phenomena in Clusters and Nanostructures, Springer-Verlag GmbH \& Co. KG, Berlin and Heidelberg, 2003, pp. 159-198.

[29] L. Li, A.H. Larsen, N.A. Romero, V.A. Morozov, C. Glinsvad, F. Abild-Pedersen, J. Greeley, K.W. Jacobsen, J.K. Nørskov, J. Phys. Chem. Lett. 4 (2013) 222.

[30] R. Kern, P. Müller, Surf. Sci. 392 (1997) 103.

[31] R. Loukrakpam, Q. Yuan, V. Petkov, L. Gan, S. Rudi, R. Yang, Y. Huang, S.R. Brankovic, P. Strasser, Phys. Chem. Chem. Phys. 16 (2014) 18866.

[32] D. Gokcen, Q. Yuan, S.R. Brankovic, J. Electrochem. Soc. 161 (2014) D3051.

[33] J. Greeley, M. Mavrikakis, Catal. Today 111 (2006) 52.

[34] S. Brankovic, J. Wang, R. Adžić, Surf. Sci. 474 (2001) L173.

[35] S.R. Brankovic, in:, G. Kreysa, K. Ota, R.F. Savinell (Eds.), Encycl. Appl. Electrochem., Springer, New York, 2014, pp. 423-430.

[36] A.E. Ismail, G.S. Grest, M.J. Stevens, J. Chem. Phys. 125 (2006) 1.

[37] J. Hotlos, O.M. Magnussen, R.J. Behm, Surf. Sci. 335 (1995) 129.

[38] D. Gokcen, S.-E. Bae, S.R. Brankovic, J. Electrochem. Soc. 157 (2010) D582.

[39] A. Tripathi, The New Image Processing Algorithm for Qualitative and Quantitative STM Image Data Analysis, University of Houston, 2012.

[40] Q. Yuan, A. Tripathi, M. Slavkovic, S.R. Brankovic, Zeitschrift Für Phys. Chemie 226 (2012) 965.

[41] N. Otsu, IEEE Trans. Syst. Man. Cybern. SMC-9 (1979) 62. 
[42] N.S. Marinković, M. Hecht, J.S. Loring, W.R. Fawcett, Electrochim. Acta 41 (1996) 641.

[43] G. Kresse, J. Furthmüller, Phys. Rev. B. Condens. Matter 54 (1996) 11169.

[44] G. Kresse, J. Furthmüller, Comput. Mater. Sci. 6 (1996) 15.

[45] P.E. Blöchl, Phys. Rev. B 50 (1994).

[46] G. Kresse, D. Joubert, Phys. Rev. B 59 (1999) 1758.

[47] B. Hammer, L.B. Hansen, J.K. Nørskov, Phys. Rev. B 59 (1999) 7413.

[48] M.J. Gillan, J. PhysicsCondensed Matter 1 (1989) 689.

[49] S.R. Bahn, K.W. Jacobsen, Comput. Sci. Eng. 4 (2002) 56.

[50] B.D. Cullity, S.R. Stock, Elements of X-Ray Diffraction, 3rd Editio, Prentice Hall, Upper Saddle River, NJ, 2001.

[51] H.J. Monkhorst, J.D. Pack, Phys. Rev. B 13 (1976) 5188.

[52] L. Bengtsson, Phys. Rev. B 59 (1999) 12301.

[53] N. Ikemiya, T. Senna, M. Ito, Surf. Sci. 464 (2000).

[54] I. Villegas, M.J. Weaver, J. Chem. Phys. 101 (1994) 1648.

[55] "The Science of Electrocatalyis on Bimetallic Surfaces" by P.N. Ross Jr., in: J. Lipkowski, P.N. Ross (Eds.), Electrocatalysis, 1st ed., Wiley-VCH, New York, 1998, pp. 43-74.

[56] S.A. Wasileski, M.T.M. Koper, M.J. Weaver, J. Phys. Chem. B 105 (2001) 3518.

[57] I. Villegas, M.J. Weaver, J. Chem. Phys. 101 (1994) 1648.

[58] P.J. Feibelman, B. Hammer, J.K. Nørskov, F. Wagner, M. Scheffler, R. Stumpf, R. Watwe, J. Dumesic, J. Phys. Chem. B 105 (2001) 4018.

[59] I. Grinberg, Y. Yourdshahyan, A.M. Rappe, J. Chem. Phys. 117 (2002) 2264.

[60] F. Abild-Pedersen, M.P. Andersson, Surf. Sci. 601 (2007) 1747. 
[61] S.R. Brankovic, N.S. Marinkovic, J.X. Wang, R.R. Adžić, J. Electroanal. Chem. 532 (2002) 57.

[62] A.A. Peterson, L.C. Grabow, T.P. Brennan, B. Shong, C. Ooi, D.M. Wu, C.W. Li, A. Kushwaha, A.J. Medford, F. Mbuga, L. Li, J.K. Nørskov, Top. Catal. 55 (2012) 1276 . 